\section{Highlights for this issue}

Anne Lingford-Hughes, Stuart Watson and Allan Young

\section{Treatment-resistant mood disorders: towards better understanding and treatment}

Mood disorders largely comprise major depressive disorder (MDD) and bipolar disorder, with treatment-resistant forms of both being common. MDD is a highly prevalent and frequently disabling illness, which requires adequate detection followed by effective treatment to reduce symptoms and improve quality of life. ${ }^{1}$ Although psychological treatment approaches are commonly employed, all extant national and international clinical guidelines recommend the use of antidepressant medication for the treatment of moderate to severe MDD. However, perhaps as many as $50 \%$ of patients fail to obtain an optimal outcome after both first- and second-line treatments; although definitions vary, these individuals are commonly described as suffering from treatment-resistant depression (TRD). ${ }^{2}$ TRD is a common problem and, compared with MDD in general, is associated with a generally poorer prognosis, higher mortality and higher healthcare utilisation costs. ${ }^{3}$ Many patients with depression are undertreated, ${ }^{4}$ but adequate treatment of TRD has been shown to improve the individual's prognosis, ${ }^{5}$ highlighting the importance of appropriate therapy for this condition.

Treatment algorithms for patients with TRD include the options of increasing the dose of the antidepressant which the patient is taking, switching to another antidepressant, or augmenting the first antidepressant with a second agent. ${ }^{6}$ Increasing the dose of medication may be associated with a statistically significantly increase in efficacy for some antidepressants, but not for many. ${ }^{7}$ Switching to an alternative antidepressant is recommended in cases where a patient has either made no response or is not tolerating their current drug. ${ }^{6}$ However, large-scale studies have shown that remission rates for third- or fourth-line antidepressant treatments are in the order of just $10-15 \%{ }^{8}$ For patients with TRD, where there is a partial response to the antidepressant they are currently receiving, augmentation with another pharmacological agent is recommended. ${ }^{6}$

The efficacy of combinations of multiple antidepressants has been brought into question by the largest clinical trial that examined this, which showed antidepressant monotherapy to be as effective as antidepressant combinations, ${ }^{9}$ although there is meta-analytic evidence to support some other particular antidepressant combinations. ${ }^{10}$ However, the efficacy of lithium augmentation of antidepressants is supported by robust evidence, which has been confirmed in a methodologically rigorous meta-analysis. ${ }^{11}$ This meta-analysis examined the efficacy of lithium in ten randomised controlled trials and found that lithium augmentation had significant benefits compared with placebo, with an odds ratio of 3.11 corresponding to a number needed to treat of 5 and a mean response rate of $41.2 \%$ (versus $14.4 \%$ in the placebo group). Recent guidance $^{12}$ has emphasised that add-on alternative treatments are a standard treatment pathway for TRD. The first-line options include lithium and the atypical antipsychotic quetiapine. For example, lithium was recommended as the first-choice add-on treatment for treating patients with TRD by the World Federation of Societies of Biological Psychiatry Task Force, ${ }^{13}$ and lithium augmentation of antidepressants is a first-line treatment option recommended by both the National Institute of Health and Care Excellence (NICE) and the current British Association for Psychopharmacology (BAP) guidelines for treating depression non-responsive to antidepressants. ${ }^{6}$ It should also be noted that although lithium has been most often associated with the treatment of bipolar disorder, it has a good evidence base showing clear-cut benefits to the patient when used in unipolar depression. ${ }^{14}$

Bipolar disorder has a lifetime prevalence of $2.5 \%{ }^{15}$ and is associated with an 8-12-year reduction in life expectancy. ${ }^{16}$ Patients with bipolar disorder are symptomatic around $50 \%$ of the time, the vast majority of which involves depression. ${ }^{17,18}$ There are three agents whose evidence base has led to their recommendation by NICE for the treatment of bipolar depression: namely, lamotrigine, quetiapine and olanzapine (with or without fluoxetine). ${ }^{19}$ The value of these drugs is reduced by the need for slow upward dose titration (lamotrigine), or by metabolic side-effects and sedation (quetiapine and olanzapine). ${ }^{20,21}$ The evidence of efficacy for a fourth agent, lurasidone, has been made available after publication of the NICE guidance. ${ }^{22,23}$ There is an absence of convincing evidence of efficacy for standard antidepressants in bipolar depression; despite this, around $70 \%$ of currently depressed bipolar patients in the UK are on at least one antidepressant. ${ }^{24}$

Cognitive therapy and early warning sign identification (and other aspects of psychoeducation), delivered to those at risk or during remission, have been shown by some $\mathrm{e}^{25-29}$ but not all ${ }^{30-32}$ studies to reduce the likelihood of the development of depression. During bipolar depression, the benefit of psychological treatments is greater in those earlier in their illness histories, with a shorter duration of current episode and fewer previous episodes. ${ }^{33,34}$ Nonetheless, overall, the Systematic Treatment Enhancement Program for Bipolar Disorder data suggest the value in bipolar depression of augmenting pharmacological treatments with cognitive therapy and other intensive psychotherapies. ${ }^{35}$

There is not an established consensus definition for TRD in people with bipolar disorder; however, it has been shown that around $50 \%$ of patients remain depressed at six months, and 30\% at a year, because of treatment non-response, intolerance or nonadherence. ${ }^{36}$ Therefore, with respect to bipolar disorder, TRD is a major contributor to the burden of disease, including estimated annual UK costs of $£ 5.2$ billion, with direct National Health Service costs of $£ 342$ million at 2010 prices. ${ }^{37,38}$ There are also all the costs, personal and financial, associated with a greater suicide risk. ${ }^{39,40}$ Current developments in the treatment of resistant bipolar depression, such as pramipexole, ketamine and vagal nerve stimulation, are therefore particularly welcomed.

As this special edition illustrates, there is a range of possible approaches to understanding and treating TRD. A number of 'high-tech' strategies including 'multi-omics', neuroimaging and 'big data' are being applied to answer this challenge. Multi-omics offers the opportunity to understand the flow of information that underlies disease - a great unmet need in psychiatry. ${ }^{41}$ Various neuroimaging approaches are already paying dividends in understanding mood disorders, ${ }^{42}$ and big data is being applied to depression. ${ }^{43}$ However, it is also important to remember the 'basics' and revisit the diagnosis by comprehensively assessing any contributing factors, as well as noting which approaches have been tried and their relative success or failure. For instance, alcohol use disorders are among the most common comorbidities of depression or bipolar disorder, and the risk of depression or bipolar disorder is heightened in those with an alcohol use disorder. ${ }^{44,45}$ However, routine screening for alcohol or other drug use, or adequate assessment when there may be a problem, generally remains woefully lacking. In bipolar disorder, comorbid alcohol use disorder is associated with a delay in diagnosis of bipolar disorder and the likelihood of greater morbidity. ${ }^{46}$ From a specialist addiction service perspective, it is not uncommon for referred individuals to have 'tried' several different antidepressants without much improvement in their mood. Then, their excessive drinking comes to light, resulting in a switch of 
focus. Despite their widespread use, there is considerable evidence that antidepressants do not substantially improve mood or alcohol consumption in those with alcoholism, or with alcohol use disorder and depression. ${ }^{47,48}$ Indeed, there is some evidence that selective serotonin reuptake inhibitors in non-depressed patients with alcoholism can make alcohol outcomes worse and not improve mood. ${ }^{47}$ Furthermore, it is well known that depressive and anxiety symptoms improve within days to weeks when someone stops drinking alcohol, so support to achieve this should be a priority and not ignored or overcome by nihilism.

In this special edition, an operational definition of treatment resistance and multi-therapy resistance in bipolar depression is proposed (Stokes pp. 27-35). There may not be widespread consensus on this, yet the argument is convincingly made that the way that we conceptualise TRD needs to be rethought and made more robust (Mahli pp. 1-3). Both the genetic aetiology (Fabbri pp. 36-41) and inflammatory pathophysiology (Chamberlain pp. 11-19) are examined, and treatment is considered from three angles: the prognostic significance of early treatment response (de Vries pp. 4-10), a meta-analysis of established augmentation strategies (Strawbridge pp. 42-51) and an evaluation of whether the short-term benefits of ketamine can be sustained via oral ambulatory therapy (Domany pp. 20-26). Together, these papers challenge and enlighten, providing a powerful argument against the hopelessness that too often afflicts patients and practitioners alike. Treatmentresistant mood disorders are among the leading challenges for clinical psychiatry today. We hope these papers suggest future prospects for better understanding and treatment.

1 Kessler R, Berglund P, Demler O, Jin R, Koretz D, Merikangas K, et al. National comorbidity survey replication. J Am Med Assoc 2003; 289(23): 3095-105.

2 Trevino K, McClintock S, McDonald Fischer N, Vora A, Husain M. Defining treatment-resistant depression: a comprehensive review of the literature. Ann Clin Psychiatry 2014; 26(3): 222-32.

3 Olchanski N, Mclnnis Myers M, Halseth M, Cyr PL, Bockstedt L, Goss TF, et al. The economic burden of treatment-resistant depression. Clin Ther 2013; 35(4): 512-22.

4 McIntyre RS, Filteau M-J, Martin L, Patry S, Carvalho A, Cha DS, et al. Treatmentresistant depression: definitions, review of the evidence, and algorithmic approach. J Affect Disord 2014; 156: 1-7

5 Wooderson SC, Fekadu A, Markopoulou K, Rane L, Poon L, Juruena MF, et al. Long-term symptomatic and functional outcome following an intensive inpatient multidisciplinary intervention for treatment-resistant affective disorders. J Affect Disord 2014; 166: 334-42.

6 Cleare A, Pariante C, Young A, Anderson I, Christmas D, Cowen P, et al. Evidence-based guidelines for treating depressive disorders with antidepressants: a revision of the 2008 British Association for Psychopharmacology guidelines. J Psychopharmacol 2015; 29(5): 459-525.

7 Rink L, Braun C, Bschor T, Henssler J, Franklin J, Baethge C. Dose increase versus unchanged continuation of antidepressants after initial antidepressant treatment failure in patients with major depressive disorder: a systematic review and meta-analysis of randomized, double-blind trials. J Clin Psychiatry 2018; 79(3): 17r11693.

8 Dunner D, Rush A, Russell J, Burke M, Woodard S, Wingard P, et al. Prospective, long-term, multi-center study of the naturalistic outcomes of patients with treatment-resistant depression. J Clin Psychiatry 2006; 67(5): 688-95.

9 Rush AJ, Trivedi MH, Stewart JW, Nierenberg AA, Fava M, Kurian BT, et al. Combining medications to enhance depression outcomes (CO-MED): acute and long-term outcomes of a single-blind randomized study. Am J Psychiatry 2011; 168(7): 689-701.

10 Henssler J, Bschor T, Baethge C. Combining antidepressants in acute treatment of depression: a meta-analysis of 38 studies including 4511 patients. Can J Psychiatry 2016; 61(1): 29-43.

11 Bauer M, Adli M, Ricken R, Severus E, Pilhatsch M. Role of lithium augmentation in the management of major depressive disorder. CNS Drugs 2014; 28(4): 331-42.

12 Bauer M, Severus E, Möller H-J, Young AH. Pharmacological treatment of unipolar depressive disorders: summary of WFSBP guidelines. Int J Psychiatry Clin Pract 2017; 21(3): 166-76.

13 Bauer M, Pfennig A, Severus E, Whybrow PC, Angst J, Möller H-J. World Federation of Societies of Biological Psychiatry (WFSBP) Guidelines for
Biological Treatment of Unipolar Depressive Disorders, Part 1: update 2013 on the acute and continuation treatment of unipolar depressive disorders. World $\mathrm{J}$ Biol Psychiatry 2013; 14(5): 334-85.

14 Young $\mathrm{AH}$. Lithium for long-term treatment of unipolar depression. Lancet Psychiatry 2017; 4(7): 511-2.

15 Clemente AS, Diniz BS, Nicolato R, Kapczinski FP, Soares JC, Firmo JO, et al. Bipolar disorder prevalence: a systematic review and meta-analysis of the literature. Rev Bras Psiquiatr 2015; 37(2): 155-61.

16 Kessing LV, Vradi E, Andersen PK. Life expectancy in bipolar disorder. Bipolar Disord 2015; 17(5): 543-8.

17 Judd LL, Akiskal HS, Schettler PJ, Coryell W, Endicott J, Maser JD, et al. A prospective investigation of the natural history of the long-term weekly symptomatic status of bipolar II disorder. Arch Gen Psychiatry 2003; 60: 261-9.

18 Judd LL, Akiskal HS, Schettler PJ, Endicott J, Maser J, Solomon DA, et al. The long-term natural history of the weekly symptomatic status of bipolar I disorder. Arch Gen Psychiatry 2002; 59: 530-7.

19 National Institute for Health and Care Excellence. Bipolar Disorder: Assessment and Management. CG185. NICE, 2014.

20 Calabrese JR, Keck Jr. PE, Macfadden W, Minkwitz M, Ketter TA, Weisler RH, et al. A randomized, double-blind, placebo-controlled trial of quetiapine in the treatment of bipolar I or II depression. Am J Psychiatry 2005; 162(7): 1351-60.

21 Tohen M, Vieta E, Calabrese J, Ketter TA, Sachs G, Bowden C, et al. Efficacy of olanzapine and olanzapine-fluoxetine combination in the treatment of bipolar I depression. Arch Gen Psychiatry 2003; 60(11): 1079-88.

22 Loebel A, Cucchiaro J, Silva R, Kroger H, Hsu J, Sarma K, et al. Lurasidone monotherapy in the treatment of bipolar I depression: a randomized, doubleblind, placebo-controlled study. Am J Psychiatry 2014; 171(2): 160-8.

23 Loebel A, Cucchiaro J, Silva R, Kroger H, Sarma K, Xu J, et al. Lurasidone as adjunctive therapy with lithium or valproate for the treatment of bipolar I depression: a randomized, double-blind, placebo-controlled study. Am J Psychiatry 2014; 171(2): 169-77.

24 POMH-UK. Topic 15a Baseline Audit Report. Prescribing Valproate for Bipolar Disorder (CCQI222). 2016

25 Brent DA, Brunwasser SM, Hollon SD, Weersing VR, Clarke GN, Dickerson JF, et al. Effect of a cognitive-behavioral prevention program on depression 6 years after implementation among at-risk adolescents: a randomized clinical trial. JAMA Psychiatry 2015; 72(11): 1110-8.

26 Colom F. 5 Year Efficacy of Group Psychoeducation. Barcelona: 5th European Stanley Conference on Bipolar Disorder, 2006.

27 Lam DH, Hayward P, Watkins ER, Wright K, Sham P. Relapse prevention in patients with bipolar disorder: cognitive therapy outcome after 2 years. Am J Psychiatry 2005; 162(2): 324-9.

28 Kessing LV, Hansen HV, Hvenegaard A, Christensen EM, Dam H, Gluud C, et al. Treatment in a specialised out-patient mood disorder clinic v. standard outpatient treatment in the early course of bipolar disorder: randomised clinical trial. Br J Psychiatry 2013; 202(3): 212-9.

29 Miklowitz DJ. Adjunctive psychotherapy for bipolar disorder: state of the evidence. Am J Psychiatry 2008; 165(11): 1408-19.

30 Lobban F, Gamble C, Kinderman P, Taylor L, Chandler C, Tyler E, et al. Enhanced relapse prevention for bipolar disorder-ERP trial. A cluster randomised controlled trial to assess the feasibility of training care coordinators to offer enhanced relapse prevention for bipolar disorder. BMC Psychiatry 2007; 7: 6 .

31 Morriss R, Lobban F, Riste L, Davies L, Holland F, Long R, et al. Clinical effectiveness and acceptability of structured group psychoeducation versus optimised unstructured peer support for patients with remitted bipolar disorder (PARADES): a pragmatic, multicentre, observer-blind, randomised controlled superiority trial. Lancet Psychiatry 2016; 3(11): 1029-38.

32 Perry A, Tarrier N, Morriss R, McCarthy E, Limb K. Randomised controlled trial of efficacy of teaching patients with bipolar disorder to identify early symptoms of relapse and obtain treatment. BMJ 1999; 318(7177): 149-53.

33 Peters A, Sylvia LG, Magalhaes PV, Miklowitz DJ, Frank E, Otto MW, et al. Age at onset, course of illness and response to psychotherapy in bipolar disorder: results from the Systematic Treatment Enhancement Program for Bipolar Disorder (STEP-BD). Psychol Med 2014; 44(16): 3455-67.

34 Scott J, Paykel E, Morriss R, Bentall R, Kinderman P, Johnson T, et al. Cognitivebehavioural therapy for severe and recurrent bipolar disorders: randomised controlled trial. Br J Psychiatry 2006; 188: 313-20.

35 Miklowitz DJ, Otto MW, Frank E, Reilly-Harrington NA, Wisniewski SR, Kogan JN, et al. Psychosocial treatments for bipolar depression: a 1-year randomized trial from the Systematic Treatment Enhancement Program. Arch Gen Psychiatry 2007; 64(4): 419-26

36 Kupfer DJ, Frank E, Grochocinski VJ, Luther JF, Houck PR, Swartz HA, et al. Stabilization in the treatment of mania, depression and mixed states. Acta Neuropsychiatr 2000; 12(3): 110-4. 
37 McCrone P, Dhanasiri S, Patel A, Knapp M, Lawton-Smith S. Paying the Price: The Cost of Mental Health Care in England to 2026. The King's Fund, 2008.

38 Young AH, Rigney U, Shaw S, Emmas C, Thompson JM. Annual cost of managing bipolar disorder to the UK healthcare system. J Affect Disord 2011; 133(3): 450-6.

39 Clements C, Morriss R, Jones S, Peters S, Roberts C, Kapur N. Suicide in bipolar disorder in a national English sample, 1996-2009: frequency, trends and characteristics. Psychol Med 2013; 43(12): 2593-602.

40 Hawton K, Sutton L, Haw C, Sinclair J, Harriss L. Suicide and attempted suicide in bipolar disorder: a systematic review of risk factors. J Clin Psychiatry 2005: 66(6): 693-704

41 Hasin Y, Seldin M, Lusis A. Multi-omics approaches to disease. Genome Biol 2017; 18(1): 83

42 Wise TMarwood L, Perkins AM, Herane-Vives A, Williams SCR, Young AH, Cleare AJ, Arnone D. A morphometric signature of depressive symptoms in unmedicated patients with mood disorders. Acta Psychiatr Scand 2018; 138(1): 73-82.
43 Eichstaedt JC, Smith RJ, Merchant RM, Ungar LH, Crutchley P, Preotiuc-Pietro D, Asch DA, Schwartz HA. Facebook language predicts depression in medical records. Proc Natl Acad Sci USA 2018; doi: 10.1073/pnas.1802331115.

44 Boden JM, Fergusson DM. Alcohol and depression. Addiction 2011; 106(5): 906-14.

45 Di Florio A, Craddock N, van den Bree M. Alcohol misuse in bipolar disorder. A systematic review and meta-analysis of comorbidity rates. Eur Psychiatry 2014; 29(3): 117-24.

46 Patel S, Shetty H, Jackson R, Broadbent M, Stewart R, Boydell J, et al. Delays before diagnosis and initiation of treatment in patients presentating to mental health services with bipolar disorder. PLOS ONE 2015; 10(5): e0126530.

47 Lingford-Hughes A, Welch S, Peters L, Nutt D, British Association for Psychopharmacology ERG. BAP updated guidelines: evidence-based guidelines for the pharmacological management of substance abuse, harmful use, addiction and comorbidity: recommendations from BAP. $J$ Psychopharmacology 2012; 26(7): 899-952.

48 Agabio R, Trogu E, Pani PP. Antidepressants for the treatment of people with co-occurring depression and alcohol dependence. Cochrane Database Syst Rev 2018; 4: CD008581. 